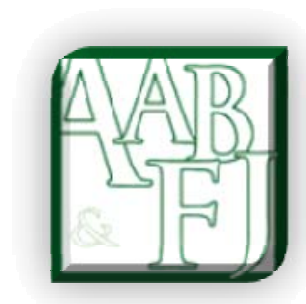

\title{
Rethinking the Lintnerian Linear Valuation Model
}

\author{
Shih-Cheng Lee ${ }^{1}$, Jiun-Lin Chen², Shu-Chen Lu³ and Lei $\mathrm{Xu}^{4}$
}

\section{Abstract}

This paper develops and tests a new valuation model. Callen and Morel (2000) apply the Lintner (1956) dividend model to the famous Ohlson (1995) valuation model and develop the Lintnerian linear accounting valuation model (henceforth, the CM model). However, Bauer and Bhattacharyya (2007) suggest that the Lintner dividend model does not fit firm dividend policy behaviour appropriately and decide to construct another dividend policy process. This study applies their dividend model to construct a new valuation model, which performs better than the original Ohlson and CM models empirically.

Applying the Engle and Granger (1987) cointegration concepts, we examine the performance of the three models for the 1,564 firm-year panel data of US companies from 1973 to 2006. Our findings indicate that all tested variables are stationary after the first order difference process and that all three models exhibit long-run equilibrium relations among equity price and explanatory variables. However, our model has the highest cointegration ratio, which is almost 100 percent of sample firms. Hence, our model is more suitable to evaluate the equity value and provides improvement for the previous accounting valuation models.

JEL Classification: M41, F36 and C52

Keywords: Ohlson Model, Lintner Model, ADF Test, Engle and Granger Test

\footnotetext{
${ }^{1}$ Faculty of Finance, Yuan Ze University, Taiwan; School of Accounting and Finance, University of Adelaide

${ }^{2}$ School of Accounting and Finance, University of Adelaide (alex.chen@adelaide.edu.au)

${ }^{3}$ College of Management, Yuan Ze University, Taiwan

${ }^{4}$ The Centre of Applied Financial Studies, School of Commerce, University of South Australia
} 


\section{Introduction}

The Ohlson (1995) accounting valuation model has received considerable attention due to its significance in assessing stock price. In his famous model, Ohlson does not set any constraint for the dividend behaviour. Later, Callen and Morel (2000) apply the Lintner (1956) dividend model to the Ohlson (1995) model and develop the Lintnerian linear accounting valuation model (henceforth, the CM model). Lin et al. (2005) extend the Ohlson (1995) model and include dividend information to the valuation model. Their result shows that dividend information has value relevance to a firm's equity price.

However, Bauer and Bhattacharyya (2007) show that the Lintner (1956) dividend model has several problems. Firstly, according to Bond and Mougoue (1991), if earnings follow an autoregressive process, the Lintner's dividend process will be an inappropriate process to model a firm's dividend policy. Since the CM model applies the Lintner model to the Ohlson model under the assumption that earnings follow an autoregressive process, the CM model suffers from the logical paradox. Secondly, if a firm has its goal of payout rate and wants to achieve it, the targeted payout ratio of the firm will be realised eventually. However, it is difficult to ask the Lintner's dynamic dividend behaviour to stop at the goal of payout rate. Thus, Bauer and Bhattacharyya (2007) establish an alternative dividend process to describe the dynamic behaviour of dividend policy. In this study, we apply the dividend model of Bauer and Bhattacharyya (2007) to the Ohlson (1995) model and develop a new valuation model which is superior to the Ohlson (1995) and CM models empirically.

Prior researchers usually used cross-sectional or time-series approaches to test accounting valuation models. The former method, which focuses on the fundamental values and simultaneously tracks the stock prices and returns, is more popular in the literature (Abarbanell \& Bernard 2000; Dechow et al. 1999; Francis et al. 2000; Penman \& Sougiannis 1998). However, it encounters a practical limitation due to the time-series nature of the accounting valuation model. Thus, recent empirical studies (Ahmed et al. 2000; Ballester et al. 2002; Callen \& Morel 2000) have adopted the time-series approach, examining the time-series relation among equity price, book values, earnings and other value-relevant variables.

However, the time-series approach still has potential drawbacks. For example, Granger and Newbold (1974) and Phillips (1986) have shown that the ordinary least squares (OLS) regressions in nonstationary time-series data could generate spurious results. Therefore, accounting valuation models may also suffer from these problems. Qi et al. (2000) conduct the unit root test of Phillips and Perron (1988) to 95 US firms and find that market values for most of the sample firms are nonstationary. To avoid misleading interpretations of the OLS regression model, it is important to verify the cointegration of accounting variables with equity value. In this paper, we use the Engle and Granger (1987) test to examine cointegration 
and stationarity of the variables in three different valuation models first, and then compare the effectiveness of the Ohlson, CM and our models.

Karathanassis and Spilioti (2003) employed panel data analysis to compare the explanation ability of the Ohlson model with that of the dividend valuation model. The panel data approach not only renders more efficient and unbiased estimators but also allows more degrees of freedom for estimation. Similarly, we use the panel data approach in this study. According to the result of 1,564 firm-year panel data of US companies from 1973 to 2006, all three models have long-run equilibrium relations. However, our model, which follows the Bauer and Bhattacharyya (2007) dividend model and applies more complicated current earnings, cointegrates for almost 100 percent of sample firms and shows superior ability to describe equity value.

The remainder of the paper is as follows. Section 2 reviews the relevant literature and section 3 discusses our research design and sample selection. Section 4 presents our empirical results and section 5 concludes.

\section{Literature Review}

\subsection{Ohlson Model}

The underlying mathematics of the Ohlson (1995) model has been described extensively in the literature. With three fundamental assumptions including the dividend discount model (DDM), the clean surplus accounting relationship (CSR), and the linear information dynamics (LID), Ohlson (1995) shows that market value of firm is equal to book value plus a linear function of current residual income and a scalar variable which represents other information.

$$
V_{t}=B V_{t}+\alpha_{1} R I_{t}+\alpha_{2} v_{t}
$$

\section{Where:}

$V_{t}=$ the market value of the firm's equity at date $t$, $B V_{t}=$ (net) book value at date $t$,

$R I_{t}=$ the residual income (abnormal earnings), defined as current accounting earnings minus a cost for the capital use (the product of the beginning book value and the cost of capital),

$v_{t}=$ information other than residual income, $\alpha_{1}, \alpha_{2}=$ parameters. 
Equation (2-1) suggests the dependency of the market value on the book value, where the book value is adjusted for (i) the current profitability measured by the abnormal earnings, and (ii) other information modifying the prediction of future profitability.

\subsection{Lintner Linear Model}

The Ohlson (1995) model doesn't set any constraint on dividends. Later, Callen and Morel (2000) apply the Lintner (1956) dividend model to the Ohlson (1995) model and develop the Lintnerian linear valuation model. In the Lintner (1956) dividend model, he assumes that firms have a constant target payout ratio to reflect the reluctance of managers to increase dividends unless earnings increase permanently. Accordingly, Callen and Morel assume that firms establish real dividends by comparing target dividends with the return on last year's book value of equity. Their dividend policy can be modeled as below:

$$
d_{t}-\left(R_{f}-1\right) B V_{t-1}=e\left[d_{t}^{*}-\left(R_{f}-1\right) B V_{t-1}\right]
$$

\section{Where:}

e is the adjustment speed,

$d_{t}^{*}$ is target dividend,

$R_{f}$ is one plus the firm's required rate of return for equity, and

$B V_{t-1}$ is the beginning book value of equity at period $t$.

They combine this equation with a fixed long-run target payout ratio to develop a new dividend dynamic model as below:

$$
d_{t}=e k^{*} N I_{t}+(1-e)\left(R_{f}-1\right) B V_{t-1}
$$

where $k^{*}$ is the target payout and $N I_{t}$ is earnings for the period from time $t-1$ to $t$. With other assumptions similar to those of Ohlson model (DDM, CSR and LID), Callen and Morel develop their Lintnerian accounting valuation model as below:

$$
V_{t}=o_{t}+\frac{\omega\left(1-e+k^{*} e\right)}{\left(R_{f}-\omega\right)(2-e)} N I_{t}+\frac{1-e}{2-e} B V_{t}
$$

where $o_{t}$ is the intercept term and $\omega$ is the parameter of the process. 


\subsection{Bauer and Bhattacharyya Dividend Model}

Bauer and Bhattacharyya (2007) show that the Lintner (1956) dividend model has theoretical drawbacks and fails to fit firm dividend policy behaviour appropriately. Therefore, they develop another dividend model by assuming that earnings and dividend can be expressed as below:

$$
\begin{aligned}
& N I_{t+1}=N I_{t}+\theta \ln \left(N I_{t}-d_{t}\right) \\
& \frac{d_{t}}{N I_{t}}=r_{t}
\end{aligned}
$$

The earnings in time $t+1$ is equal to the earnings in time $t$ and the reward produced due to investment out of earnings in time $t$. The logarithmic function reflects the diminishing return to investment and $\theta$ is a function that models the impact of exogenous variables and traps managers' inter-temporal allocation decisions. Firm managers consider the following optimisation problem and choose $r_{t}$ to maximum the expected total payoff for the shareholders.

$$
\underset{r_{t}}{\operatorname{Max}} d_{t}+E\left(N I_{t+1}\right)
$$

Bauer and Bhattacharyya show that their model performs well empirically in cross-sectional Tobit regression and time series fitting. Specifically, the results of the Tobit regression are quite consistent with the predictions of their model. In the time series testing, their model can fit the empirical data in $96 \%$ of the cases for firms with longer data series of 35 years or more.

\section{Research Design}

\subsection{Valuation Model of This Study}

Our model incorporates the spirit of the Bauer and Bhattacharyya (2007) dividend model and follows similar assumptions of the Ohlson (1995) model. Equity price is the present value of expected future dividends under current information (DDM). The clean surplus relation remains unchanged and earnings follow first order autoregressive processes. Compared to the CM model, our model uses the Bauer and Bhattacharyya dividend model to describe the dividend behaviour. Thus, our model can be described as below: 


$$
\begin{aligned}
& V_{t}=\sum_{\tau=1}^{\infty} R^{-\tau} E_{t}\left(d_{t+\tau}\right) \quad \text { (dividend discount model) } \\
& B V_{t}=B V_{t-1}+N I_{t}-d_{t} \quad \text { (clean surplus relation) } \\
& N I_{t}=\omega N I_{t-1}+\gamma v_{t}+\varepsilon_{1, t+1} \\
& v_{t+1}=\quad \gamma v_{t}+\varepsilon_{2, t+1} \\
& N I_{t}=N I_{t-1}+\theta \ln \left(N I_{t-1}-d_{t-1}\right) \quad \text { (dividend policy) }
\end{aligned}
$$

Where:

$V_{t}=$ the market value of equity at date $t$, $d_{t}=$ net dividends paid at date $t$, $N I_{t}=$ earnings for the period from time $t-1$ to $t$, $B V_{t}=$ (net) book value at date $t$, $\theta, \omega, \gamma=$ parameters of the processes, $v_{t}=$ information other than residual income, $\varepsilon_{1, t+1}, \varepsilon_{2, t+1}=$ unpredictable mean-zero disturbance terms.

Equation (3-4) suggests that earnings are affected by not only previous earnings but also by the return of investment decision proposed by Bauer and Bhattacharyya (2007). Besides, $\theta$ presents managers' real investment decisions.

We combine equation (3-2) and (3-4) to yield the following equation:

$$
d_{t}=N I_{t+1}-\left(B V_{t}-B V_{t-1}\right)-\theta \ln \left(B V_{t}-B V_{t-1}\right)
$$

This equation shows that current dividends payout is affected by the next earnings and the difference of book value of common stock equity. It is different from the dividend model of the CM model showed in equation (2-3), which emphasises the relation of current dividends to current earnings and last book value of common stock equity.

Finally, we apply the Bauer and Bhattacharyya (2007) dividend model and develop our valuation model as the following (details are shown in the appendix):

$$
V_{t}=\frac{\omega}{R_{f}-\omega} N I_{t}+\frac{e^{\frac{\omega N I_{t}(\omega-1)}{\theta}}}{e^{\frac{\omega N I_{t}(\omega-1)^{2}}{\theta}}-R_{f}}
$$


where $R_{f}$ is one plus the risk-free interest rate. Although both models have similar assumptions with the Ohlson (1995) model, the same item of our model and the CM model is only the first item in equation (3-6). The second item, consisting of the natural exponential element and $R_{f}$, presents the sum of the difference of book value of equity. Therefore, our model applies more complicated current earnings in the valuation model than the CM model, which fails to consider the influence of book value on the valuation.

\subsection{Methodology}

To test whether our model is superior to the Ohlson and CM models empirically, we employ cointegration concepts proposed by Engle and Granger (1987). Before the cointegration concept is introduced, most prior researchers use 'difference method' to resolve non-stationary problems. However, the 'difference process' would destroy valuable information in the long-term relationship between original variables. Engle and Granger suggest using the original time-series data in evaluating the long-term relationship between non-stationary variables, since cointegration implies that long-term equilibrium can still exist even for non-stationary variables.

The procedures for the cointegration test are as follows. Firstly, the unit root test is conducted to determine whether a variable is stationary and whether all variables have the same order of integration. This step is quite important since all variables should be integrated of the same order if the cointegration relationship exists. If the result shows that two variables $\left(y_{t}\right.$ and $z_{t}$ ) are integrated in the first order, we can continue to estimate the long-run relationship: $y_{t}=\beta_{0}+\beta_{1} z_{t}+e_{t}$. The residual series from this equation, $\hat{e}_{t}$, measures the deviations from the long run relationship. If $\hat{e}_{t}$ is stationary, the variables $y_{t}$ and $z_{t}$ are cointegrated. In practice, we can conduct the unit root test to examine the residual series and determine the cointegration relation.

In this study, we test whether a long-run relationship exists among equity price and the explanatory variables in three valuation models (Ohlson 1995, CM and our model). Specifically, we run the OLS regression (called the cointegrating regression) to verify the relation of market value and explanatory variables in these valuation models. Then, we use the Augmented Dickey-Fuller Test to examine whether the residuals, $\hat{e}_{t}$, from all regressions are stationary. The existence of cointegration indicates that the evaluation model can well describe a long-term relationship between the equity price and explaining variables empirically. Finally, we compare the percentage of firms cointegrated in each model to identify which model is better. 


\subsection{Sample and Data}

Our sample firms are US-based listed firms on the NYSE, NYSE Amex and NASDAQ exchanges. All relevant data come from the COMPUSTAT and CRSP US stock databases as well as the Data Library of Kenneth R. French. The CRSP Database contains daily and monthly market data for securities with primary listings on the NYSE, NYSE Amex and NASDAQ exchanges while the COMPUSTAT database collects quarterly and yearly financial statement information. These two databases are renowned for their accuracy and are heavily used for academic research in the literature. Since we need complete panel data for all variables in our co-integration test from 1973 to 2006, our sample is reduced to 1,564 firm-years. Specifically, all selected firm-years need to meet the following criteria: (1) financial statement data are available from COMPUSTAT; (2) stock return data are available from CRSP; and (3) stock prices are different in fiscal year. These selection criteria are commonly used in the literature for US empirical study. We also use the one-month t-Bill rate from Ibbotson and Associates as the cost of capital.

\section{Empirical Results}

\subsection{Descriptive Statistics}

Table 1 reports descriptive statistics of the sample from 1973 to 2006 . The means of all variables are greater than medians, indicating that all variables have right-skewed distribution. Market value volatility (std. dev. is 20.78) is greater than book value volatility (std. dev. is 5.57). The possible reason is that book value is the accounting number from financial statements and is more stable than market value.

Table 1: Sample Descriptive Statistics

\begin{tabular}{lccccc}
\hline & Mean & Std. Dev & Q1 & Median & Q3 \\
\hline$V_{t}$ & 39.26 & 20.78 & 25.00 & 35.56 & 48.62 \\
\hline$B V_{t}$ & 5.20 & 5.57 & 1.28 & 1.68 & 7.00 \\
\hline$N I_{t}$ & 2.57 & 1.40 & 1.64 & 2.30 & 3.13 \\
\hline$R I_{t}$ & 2.13 & 1.45 & 1.21 & 1.83 & 2.69 \\
\hline$r_{t}$ & 0.12 & 0.06 & 0.10 & 0.11 & 0.16 \\
\hline$\theta$ & 0.05 & 1.20 & -0.54 & 0.03 & 0.52 \\
\hline$\omega$ & 0.48 & 0.21 & 0.36 & 0.48 & 0.59 \\
\hline
\end{tabular}


Lee, Chen, Lu \& Xu | Rethinking the Lintnerian Linear Valuation Model

Note: This table presents descriptive statistics of the sample. The units for all variables are in million dollars. $V_{t}$ is market value of common equity at the end of fiscal year $t . B V_{t}$ is book value of common equity at the end of fiscal year $t$. $N I_{t}$ is net income. $R I_{t}$ is residual income, calculated as $R I_{t}=N I_{t}-r B V_{t-1} \cdot r_{t}$ is the cost of capital, computed as yearly rate from the one-month Treasury bill. $\theta$ and $\omega$ are parameters, estimated from $N I_{t}=N I_{t-1}+\theta \ln \left(N I_{t-1}-d_{t-1}\right)$ and $N I_{t}=\omega N I_{t-1}+v_{t-1}+\varepsilon_{1, t}$ by linear ordinary least squares.

\subsection{Tests for Stationarity and Cointegration}

To test these three models empirically, we employ the cointegration method proposed by Engle and Granger (1987). Firstly, we verify whether all variables are stationary and have the same order of integration to avoid spurious regressions. From Augmented Dickey-Fuller (ADF) unit root tests without time trend (unreported), all those variables (book value, net income, residual income and market value) cannot reject the null hypothesis of nonstationarity. Therefore, we need to apply a difference process to these variables before we can test the cointegration effect.

Table 2 presents the ADF statistical results of all the variables after first order difference. All the mean and median ADF statistical values are lower than the critical value $(-2.93)$ at the 0.05 level, which rejects the null hypothesis of nonstationarity. Thus, all test variables are stationary after the first order difference process. The ratios of stationarity in market value, book value, net income, and residual income are 100, 76.09, 95.65 and 97.83 percent of sample firms respectively, which suggests the test valuables in our sample have the same order of integration. Therefore, we can continue to test the cointegration among variables in Ohlson, CM, and our model.

Table 2: Augmented Dickey-Fuller Unit Root Test of First Order Difference

\begin{tabular}{ccccccc}
\hline & Mean & Std. Dev & Q1 & Median & Q3 & Percentage of Stationarity \\
\hline$V_{t}$ & -6.65 & 1.81 & -7.70 & -6.70 & -5.27 & 100.00 \\
\hline$B V_{t}$ & -4.96 & 3.25 & -7.28 & -5.80 & -2.89 & 76.09 \\
\hline$N I_{t}$ & -6.02 & 1.55 & -6.96 & -6.23 & -5.00 & 95.65 \\
\hline$R I_{t}$ & -6.33 & 1.55 & -7.04 & -6.36 & -5.31 & 97.83 \\
\hline
\end{tabular}

Note: This table presents the statistics of the Augmented Dickey-Fuller (ADF) unit root test for all variables (market value, book value, net income and residual income) after the first order difference process. The critical value for this Augmented Dickey-Fuller unit root test without trend at the 0.05 level is -2.93 and the null hypothesis means nonstationary.

Table 3 presents the cointegration test results of the three models. First, we run the cointegrating regression and collect the residuals. Then, we test the stationarity of the residual 
to examine whether long-run equilibrium exists among the variables in these valuation models. The mean and median statistics of these models are all less than the critical value of -2.93 at the 0.05 level. Obviously, the mean and median statistics of the cointegration test in our model are the most negative among all models, indicating a stronger rejection of the null hypothesis of non-cointegration. Moreover, the standard deviation in our model for cointegration test is only 0.06 , compared to 1.11 and 1.08 in the Ohlson and CM models respectively.

The Ohlson model, without any constraint on the firm dividend policy, has $86.96 \%$ of the sample firms cointegrated in the equity evaluation. The CM model, applying Lintner's (1956) dividend policy, has $89.13 \%$ of the sample firms cointegrated. Our model, assuming the dividend policy of Bauer and Bhattacharyya (2007), has almost $100 \%$ of the sample cointergrated. This empirical result indicates that our model performs better than the Ohlson (1995) and CM models in describing the behaviour of equity value under the long-term equilibrium.

Table 3: Cointegration Test with Ohlson, $\mathrm{CM}$ and Our Model

\begin{tabular}{lcccccc}
\hline Models & Mean & Std. Dev & Q1 & Median & Q3 & Percentage of Stationary \\
\hline Ohlson & -3.79 & 1.11 & -4.45 & -3.74 & -3.17 & 86.96 \\
\hline & & & & & & \\
\hline CM & -3.93 & 1.08 & -4.61 & -3.84 & -3.24 & 89.13 \\
\hline Our Model & -5.76 & 0.06 & -5.75 & -5.74 & -5.74 & 100.00 \\
\hline
\end{tabular}

Note: This table reports the results of the cointegration test for the Ohlson, CM, and our model. The mean and median statistics of the ADF unit root test for the residual from the cointegration regression are presented. The critical value of the ADF test without trend at the 5 percent level is -2.93. The null hypothesis means no cointegration relationship.

\section{Conclusion}

This study applies the dividend policy model of Bauer and Bhattacharyya (2007) to the Ohlson (1995) valuation model to develop a new valuation model. Using the panel data of US listed firms from 1973 to 2006, we compare the empirical performance of our model with those of the Ohlson (1995) and Callen and Moral (2000) models under the cointegration method. Although all models show a long-run equilibrium relation, our model outperforms others by considering more complicated current earnings information to evaluate equity value. Specifically, almost 100 percent of the sample shows cointegration between equity value and explanatory variables in our model, which is more suitable to describe equity price than the Ohlson (1995) or Callen and Moral (2000) models. 


\section{References}

Abarbanell, J \& Bernard, V 2000, 'Is the U.S. stock market myopic', Journal of Accounting Research, vol. 38, no. 2, pp. 221-242.

Ahmed, AS, Morton, RM \& Schaefer, TF 2000, 'Accounting conservatism and the valuation of accounting numbers: Evidence on the Feltham-Ohlson (1996) model', Journal of Accounting, Auditing \& Finance, vol. 15, no. 3, pp. 271-292.

Ballester, M, Livnat, J \& Sinha, N 2002, 'Labor costs and investments in human capital', Journal of Accounting, Auditing and Finance, vol. 17, no. 4, pp. 351-373.

Bauer, L \& Bhattacharyya, N 2007, 'Rethinking Lintner: An alternative dynamic model of dividends', working paper, University of Newfoundland.

Bond, MT \& Mougoue, M 1991, 'Corporate dividend policy and the partial adjustment model', Journal of Economics and Business, vol. 43, issue 2, pp. 165-177.

Callen, JL \& Morel, M 2000, 'A Lintnerian linear accounting valuation model', Journal of Accounting, Auditing \& Finance, vol. 15, no. 3, pp. 301-314.

Dechow, PM, Hutton, AP \& Sloan, RG 1999, 'An empirical assessment of the residual income valuation model', Journal of Accounting and Economics, vol. 26, issue 1-3, pp. $1-34$.

Engle, RF \& Granger, CWJ 1987, 'Co-integration and error correction: Representation, estimation, and testing', Econometrica, vol. 55, no. 2, pp. 251-276.

Francis, J, Olsson, P \& Oswald, DR 2000, 'Comparing the accuracy and explainability of dividend, free cash flow, and abnormal earnings equity value estimates', Journal of Accounting Research, vol. 38, no. 1, pp. 45-70.

Granger, CWJ \& Newbold, P 1974, 'Spurious regressions in Econometrics', Journal of Econometrics, vol. 2, issue 2, pp. 111-120.

Karathanassis, GA \& Spilioti, SN 2003, 'An empirical investigation of the traditional and the clean surplus valuation models', Managerial Finance, vol. 29, issue 9, pp. 55-66.

Lin, YM, Hsu, YS \& Liao, W 2005, 'The relationship between dividend policy and equity valuation model', working paper, National Chung Hsing University.

Lintner, J 1956, 'Distribution of incomes of corporations among dividends, retained earnings, and taxes', American Economic Review, vol. 46, no. 2, pp. 97-113.

Ohlson, JA 1995, 'Earnings, book values, and dividends in equity valuation', Contemporary Accounting Research, vol. 11, issue 2, pp. 661-687.

Penman, SH \& Sougiannis, T 1998, 'A comparison of dividend, cash flow, and earnings approaches to equity valuation', Contemporary Accounting Research, vol. 15, issue 3, pp. 343-383.

Phillips, PCB 1986, 'Understanding spurious regressions in Econometrics', Journal of Econometrics, vol. 33, issue 3, pp. 311-340. 
AABFJ | Volume 8, no. 3, 2014

Phillips, PCB \& Perron, P 1988, ‘Testing for a unit root in time-series regression', Biometrica, vol. 75, issue 2, pp. 335-346.

Qi, D, Wu, YW \& Xiang, B 2000, 'Stationarity and cointegration tests of the Ohlson model', Journal of Accounting, Auditing and Finance, vol. 15, no. 2, pp. 141-160. 


\section{APPENDIX}

As mentioned in the text. Our model applies the following assumptions:

$$
\begin{array}{ll}
V_{t}=\sum_{\tau=1}^{\infty} R^{-\tau} E_{t}\left(d_{t+\tau}\right) & \text { (dividend discount model) } \\
B V_{t}=B V_{t-1}+N I_{t}-d_{t} & \text { (clean surplus relation) } \\
N I_{t}=\omega N I_{t-1}+\gamma v_{t}+\varepsilon_{1, t+1} & \\
v_{t+1}= & \text { (linear information dynam } \\
N v_{t}+\varepsilon_{2, t+1} & \\
N I_{t}=N I_{t-1}+\theta \ln \left(N I_{t-1}-d_{t-1}\right) & \text { (dividend policy) }
\end{array}
$$

Because of (3-5) equation, we can have the following two equations:

$$
-\theta \ln \left(\Delta B V_{t}\right)=N I_{t}-N I_{t+1}
$$

And,

$$
B V_{t}-B V_{t-1}=e^{\frac{N I_{t+1}-N I_{t}}{\theta}}
$$

Applying (3-7) and (3-8) to (3-1),

Thus,

$$
\begin{aligned}
E\left(d_{t+1}\right)=E( & \left.N I_{t+2}\right)-E\left(\Delta B V_{t+1}\right)-E\left[\theta \ln \left(\Delta B V_{t+1}\right)\right] \\
= & \omega^{2} N I_{t}-e^{\frac{N I_{t+2}-N I_{t+1}}{\theta}}+E\left(N I_{t+1}\right)-E\left(N I_{t+2}\right) \\
= & \omega^{2} N I_{t}-e^{\frac{\omega^{2} N I_{t}-\omega N I_{t}}{\theta}}+\omega N I_{t}-\omega^{2} N I_{t} \\
= & \omega N I_{t}-e^{\frac{\omega N N_{t}(\omega-1)}{\theta}} \\
E\left(d_{t+2}\right)=E & \left(N I_{t+3}\right)-E\left(\Delta B V_{t+2}\right)-E\left[\theta \ln \left(\Delta B V_{t+2}\right)\right] \\
= & \omega^{3} N I_{t}-e^{\frac{N I_{t+3}-N I_{t+2}}{\theta}}+E\left(N I_{t+2}\right)-E\left(N I_{t+3}\right) \\
= & \omega^{3} N I_{t}-e^{\frac{\omega^{3} N I_{t}-\omega^{2} N I_{t}}{\theta}}+\omega^{2} N I_{t}-\omega^{3} N I_{t} \\
= & \omega^{2} N I_{t}-e^{\frac{\omega^{2} N I_{t}(\omega-1)}{\theta}}
\end{aligned}
$$


AABFJ | Volume 8, no. 3, 2014

Generally,

$$
E\left(d_{t+k}\right)=\omega^{k} N I_{t}-e^{\frac{\omega^{k} N I_{t}(\omega-1)}{\theta}}
$$

Thus,

$$
R_{f}^{-k} E\left(d_{t+k}\right)=\left(\frac{\omega}{R_{f}}\right)^{K} N I_{t}-R_{f}^{-K} e
$$

And we assume $\mathrm{F}=\frac{\omega N I_{t}(\omega-1)}{\theta}$,

Therefore,

$$
\sum_{K=1}^{\infty} R_{f}^{-k} E\left(d_{t+k}\right)=\sum_{K=1}^{\infty}\left(\frac{\omega}{R_{f}}\right)^{K} N I_{t}-\sum_{K=1}^{\infty} R_{f} e^{-K} \frac{\omega^{k} N t_{t}(\omega-1)}{\theta}
$$

Besides,

$$
\sum_{K=1}^{\infty}\left(\frac{\omega}{R_{f}}\right)^{K} N I_{t}=\frac{\frac{\omega}{R_{f}} N I_{t}}{1-\frac{\omega}{R_{f}}}=\frac{\omega}{R_{f}-\omega} N I_{t}
$$

And,

$$
\begin{aligned}
\sum_{K=1}^{\infty} R_{f} e^{-K} \frac{\omega^{k} N I_{t}(\omega-1)}{\theta} & =R_{f}^{-1} e^{\frac{\omega N I_{t}(\omega-1)}{\theta}}+R_{f}^{-2} e^{\frac{\omega^{2} N I_{t}(\omega-1)}{\theta}} \ldots \ldots+R_{f}^{-\infty} e^{\frac{\omega^{\infty} N I_{t}(\omega-1)}{\theta}} \\
& =\frac{e^{F}}{R_{f}}+\frac{e^{\omega F}}{R_{f}{ }^{2}}+\ldots . .+\frac{e^{\omega^{\infty-1} F}}{R_{f}^{\infty}} \\
& =\frac{\frac{e^{F}}{R_{f}}}{1-\frac{e^{F(\omega-1)}}{R_{f}}}=\frac{e^{F}}{R_{f}-e^{F(\omega-1)}}=\frac{e^{\frac{\omega N I_{t}(\omega-1)}{\theta}}}{R_{f}-e^{\frac{\omega N I_{t}(\omega-1)^{2}}{\theta}}}
\end{aligned}
$$


Thus, we can get below:

$$
\begin{aligned}
\sum_{K=1}^{\infty} R^{-k} E\left(d_{t+k}\right)=\sum_{K=1}^{\infty}\left(\frac{\omega}{R_{f}}\right)^{K} N I_{t}-\sum_{K=1}^{\infty} R_{f} e^{\frac{\omega^{k} N I_{t}(\omega-1)}{\theta}} \\
=\frac{\omega}{R_{f}-\omega} N I_{t}-\frac{e^{\frac{\omega N I_{t}(\omega-1)}{\theta}}}{R_{f}-e^{\frac{\omega N I_{t}(\omega-1)^{2}}{\theta}}} \\
=\frac{\omega}{R_{f}-\omega} N I_{t}+\frac{e^{\frac{\omega N I_{t}(\omega-1)}{\theta}}}{e^{\frac{\omega N I_{t}(\omega-1)^{2}}{\theta}}-R_{f}}
\end{aligned}
$$

Finally, we can express accounting valuation as below:

$$
V_{t}=\frac{\omega}{R_{f}-\omega} N I_{t}+\frac{e^{\frac{\omega N I_{t}(\omega-1)}{\theta}}}{e^{\frac{\omega N I_{t}(\omega-1)^{2}}{\theta}}-R_{f}}+o_{t}
$$

Provided that $\omega<R_{f}$ and $e^{\frac{\omega N I_{t}(\omega-1)^{2}}{\theta}}<R_{f}$. 
AABFJ | Volume 8, no. 3, 2014 